\title{
Assessment of the feasibility of using sunlight exposure to obtain the recommended level of vitamin $\mathrm{D}$ in Canada
}

\author{
Pavandeep Gill MD, Sunil Kalia MD MHSc
}

\section{Abstract}

Background: Endogenous vitamin D synthesis can be affected by a number of variables, including skin colour, amount of skin exposed and levels of ultraviolet radiation. The objective of this study was to assess the feasibility of using only sunlight exposure in Canada to meet the daily recommended level of vitamin D, given differences in these variables and adherence to guidelines for sun protection.

Methods: Ultraviolet index data for 13 Canadian sites were obtained from Environment Canada. The sun exposure times required to synthesize $1000 \mathrm{IU}$ of vitamin D in fair- and dark-skinned people who exposed either 1/4 or 1/8 of their body surface area to the sun were calculated for each hour of the year. These times were then classified according to whether the ultraviolet index was 3 or more (when sun protection is advised) or less than 3.

Results: During the fall and winter months and in the more northern sites, ultraviolet radiation levels were too low for all skin types to use sun exposure alone to obtain enough vitamin $\mathrm{D}$ within one time period. The required exposure time became longer when a smaller surface area was exposed. For people with darker skin, it can be difficult even in the summer to find opportunities outside of when sun protection is advised to use sunlight to obtain the recommended dose of vitamin D.

Interpretation: Although sun exposure is an important source of vitamin D, Canadians should look to other safe sources to meet the body's vitamin $\mathrm{D}$ requirements throughout the year.

V itamin $\mathrm{D}$ is a major steroid hormone that helps maintain homeostatic levels of calcium and phosphorus in the body and plays an important role in the maintenance of bone health and prevention of osteoporosis. ${ }^{1}$ Studies have also linked deficiencies of vitamin $\mathrm{D}$ with breast cancer, ${ }^{2,3}$ depression ${ }^{4}$ and cardiovascular disease. ${ }^{5}$ To mitigate the adverse effects of vitamin D deficiency, Osteoporosis Canada ${ }^{6}$ and the International Osteoporosis Foundation ${ }^{7}$ recommend $1000 \mathrm{IU}$ as the standard daily dose of vitamin D in adults. Vitamin D can be obtained from dietary sources and synthesized endogenously. ${ }^{8}$

Sunlight contains ultraviolet radiation: ultraviolet B radiation acts on the epidermis and causes erythema. ${ }^{9}$ Vitamin $\mathrm{D}$ is produced when ultraviolet $\mathrm{B}$ radiation interacts with 7 dehydrocholesterol in the skin. ${ }^{10,11}$ Several variables can affect this endogenous vitamin D synthesis. Increased age, ${ }^{12}$ dark skin colour ${ }^{13}$ area of skin surface exposed ${ }^{9}$ and low levels of ultraviolet radiation are some factors that can decrease the ability of the skin to produce vitamin $\mathrm{D}$. The ultraviolet index is a scale that measures the intensity of ultraviolet radiation. It ranges from 1 to 14 , and each unit is equal to $25 \mathrm{~mW} / \mathrm{m}^{2}$ of erythemal ultraviolet radiation. ${ }^{14}$ Solar angle, cloud cover, altitude, latitude, ${ }^{15}$ ozone thickness and snow on the ground can affect ultraviolet index values. ${ }^{16}$
Although sun exposure has its benefits in vitamin $\mathrm{D}$ production, ultraviolet radiation is a risk factor for skin cancer ${ }^{17}$ and sun protection actions should be considered, especially in the spring and summer. Environment Canada, the Canadian Cancer Society and the Canadian Dermatology Association have produced guidelines for the use of sun protection whenever the ultraviolet index is above 3 . These guidelines recommend avoiding the outdoors when the ultraviolet index is above 3 or, when outside during those times, seeking shade, wearing hats, sunglasses, shoes, long pants and long-sleeved shirts, and using a sunscreen of at least SPF $15 .{ }^{18}$ Although these guidelines help reduce the risk of skin cancer, adherence to these guidelines greatly reduces the skin surface area exposed to ultraviolet radiation. Therefore, wearing protective clothing ${ }^{8}$ and sunscreens ${ }^{19}$ have been shown to reduce vitamin $\mathrm{D}$ production.

Correspondence to: Sunil Kalia,sunil.kalia@vch.ca

This article has been peer reviewed.

Competing interests: None declared.

CMAJ Open 2015. DOI:10.9778/cmajo.20140037 
The objective of this study was to assess the feasibility of only using sunlight exposure in Canada to meet the standard daily dose of vitamin D by using ultraviolet index data obtained from Environment Canada. Other factors, such as skin colour, amount of skin exposed and adherence to sun safety guidelines, were also analyzed.

\section{Methods}

\section{Background}

The minimal erythemal dose is the minimum amount of exposure to ultraviolet radiation that causes erythema of the skin. The minimal erythemal dose correlates with Fitzpatrick skin type classification (Table 1). For fair-skinned individuals with type II skin, the average minimal erythemal dose is $250 \mathrm{~J} / \mathrm{m}^{2}$ and for dark-skinned individuals with type $\mathrm{V}$ skin, the average dose is $600 \mathrm{~J} / \mathrm{m}^{2} \cdot{ }^{20}$ Holick's rule makes the assumption that $1 / 4$ of 1 minimal erythemal dose directed at $1 / 4$ of the body surface area (i.e., the face, neck, hands and full arms) allows for the production of the equivalent of $1000 \mathrm{IU}$ of oral vitamin $\mathrm{D}$, and this assumption has been used in several past studies. ${ }^{21,22}$ To produce the standard dose of vitamin $\mathrm{D}$ when a smaller body surface area, such as $1 / 8$ of the skin, was exposed (e.g., the full head), a dose of $1 / 2$ of 1 minimal erythemal dose was calculated to be required.

\section{Data source}

Average hourly ultraviolet indices were calculated using Environment Canada data for the period from 1991 to 2004. ${ }^{23}$ Data were available for 13 Canadian sites: Bedford/Dartmouth, Nova Scotia; Happy Valley-Goose Bay, Newfoundland and Labrador; Montréal/Dorval; Toronto/Downsview; Winnipeg; Churchill, Manitoba; Resolute, Nunavut; Eureka, Nunavut; Alert, Nunavut; Bratts Lake (Regina), Saskatchewan; Saskatoon; Stony Plain, Alberta; and Saturna Island, British Columbia. The ultraviolet index values were converted to erythemal ultraviolet in $\mathrm{W} / \mathrm{m}^{2}$ using the following conversion factor: 1 unit of ultraviolet index $=90 \mathrm{~J} /\left(\mathrm{h} \cdot \mathrm{m}^{2}\right)$ erythemal ultraviolet.

\begin{tabular}{|llrl|}
\hline $\begin{array}{l}\text { Table 1: Minimal erythemal dose (MED) for different skin } \\
\text { types using the Fitzpatrick scale }{ }^{20}\end{array}$ \\
\hline Type & \multicolumn{1}{|c}{ Skin colour } & $\begin{array}{c}\text { MED, } \\
\mathrm{J} / \mathrm{m}^{2}\end{array}$ & \multicolumn{1}{c|}{ Description } \\
\hline I & White or very pale & 200 & Always burns, never tans \\
\hline II & Pale white with beige tint & 250 & $\begin{array}{l}\text { Always burns, sometimes } \\
\text { tans }\end{array}$ \\
\hline III & $\begin{array}{l}\text { Beige to light brown } \\
\text { (olive) }\end{array}$ & 300 & $\begin{array}{l}\text { Sometimes burns, always } \\
\text { tans }\end{array}$ \\
\hline IV & Light to moderate brown & 450 & Rarely burns, always tans \\
\hline V & Medium to dark brown & 600 & $\begin{array}{l}\text { Rarely burns, tans more } \\
\text { than average }\end{array}$ \\
\hline VI & Dark brown to black & 1000 & Never burns \\
\hline
\end{tabular}

\section{Outcome measures and statistical analysis}

Using the calculated erythemal ultraviolet values, we used SPSS statistical software to calculate the exposure times for each hour of the day between 300 and 2000 (when measurable ultraviolet index values were available for most sites) that were required for people with type II skin to obtain $1 / 4$ of the minimal erythemal dose when $1 / 4$ of their body surface area was exposed to the sun. The required fluence for a person with type II skin to acquire the standard dose of vitamin D is $62.5 \mathrm{~J} / \mathrm{m}^{2}$. The erythemal ultraviolet during each time period was divided by this number, and this value was then converted to minutes to provide the required exposure time. Similar calculations were made for exposure times required for people with type II skin to acquire $1 / 2$ of the minimal erythemal dose when $1 / 8$ of their body was exposed and for individuals with type $\mathrm{V}$ skin to acquire $1 / 4$ and $1 / 2$ of the minimal erythemal dose with $1 / 4$ and $1 / 8$ of the body exposed. These results were recorded in tabular format showing the lowest exposure times for each month at each site.

\section{Results}

Figure 1 shows the lowest sun exposure times required to synthesize the standard dose of vitamin D for each month at each site. To include the guidelines for sun protection, periods when the ultraviolet index was less than 3 and sun protection was not necessary are in green if it was possible to synthesize the standard dose of vitamin D in 30 minutes or less and in orange if it was possible to synthesize 1000 IU between 31 and 60 minutes. Periods when it was impossible to synthesize $1000 \mathrm{IU}$ or when the ultraviolet index was too low to report are in grey, and periods when the ultraviolet index was 3 or greater and sun protection was recommended are in yellow.

The average, fair-skinned person with type II skin and with $1 / 4$ of their skin exposed (Figure 1A) had no opportunities to synthesize $1000 \mathrm{IU}$ of vitamin D during 1 hourly time period in December at 11 of the 13 sites studied. In Montréal/Dorval and Toronto/Downsview, where opportunities existed during this month, required exposure times ranging between 53 and 60 minutes (Appendix 1, available at www.cmajopen.ca/ content/3/3/E258/suppl/DC1). During the summer months, people with type II skin and with $1 / 4$ of their skin exposed were able to produce 1000 IU of vitamin D by sun exposure at all 13 sites. Adequate levels of vitamin D could be acquired in less than 30 minutes outside of times when sun protection was advised during the summer months. Exposure times ranged between 14 and 30 minutes (Appendix 1). In January, November and December, there were no opportunities for people with type II skin and with 1/8 of their skin exposed (Figure $1 \mathrm{~B}$ ) to produce $1000 \mathrm{IU}$ of vitamin D using sun exposure during an hourly time period. There were few opportunities to produce $1000 \mathrm{IU}$ in less than 30 minutes.

Dark-skinned people with type $V$ skin and with $1 / 4$ of their skin exposed (Figure 1C) were unable to produce $1000 \mathrm{IU}$ of vitamin $\mathrm{D}$ within 1 hour at any of the 13 sites during January, November and December. At 2 of the 13 sites (Montréal/ Dorval and Bratts Lake), it was possible to produce vitamin D 


\section{A. Persons with type II skin exposing $1 / 4$ of their body surface area to the sun to obtain $1 / 4$ of the minimal erythemal dose}

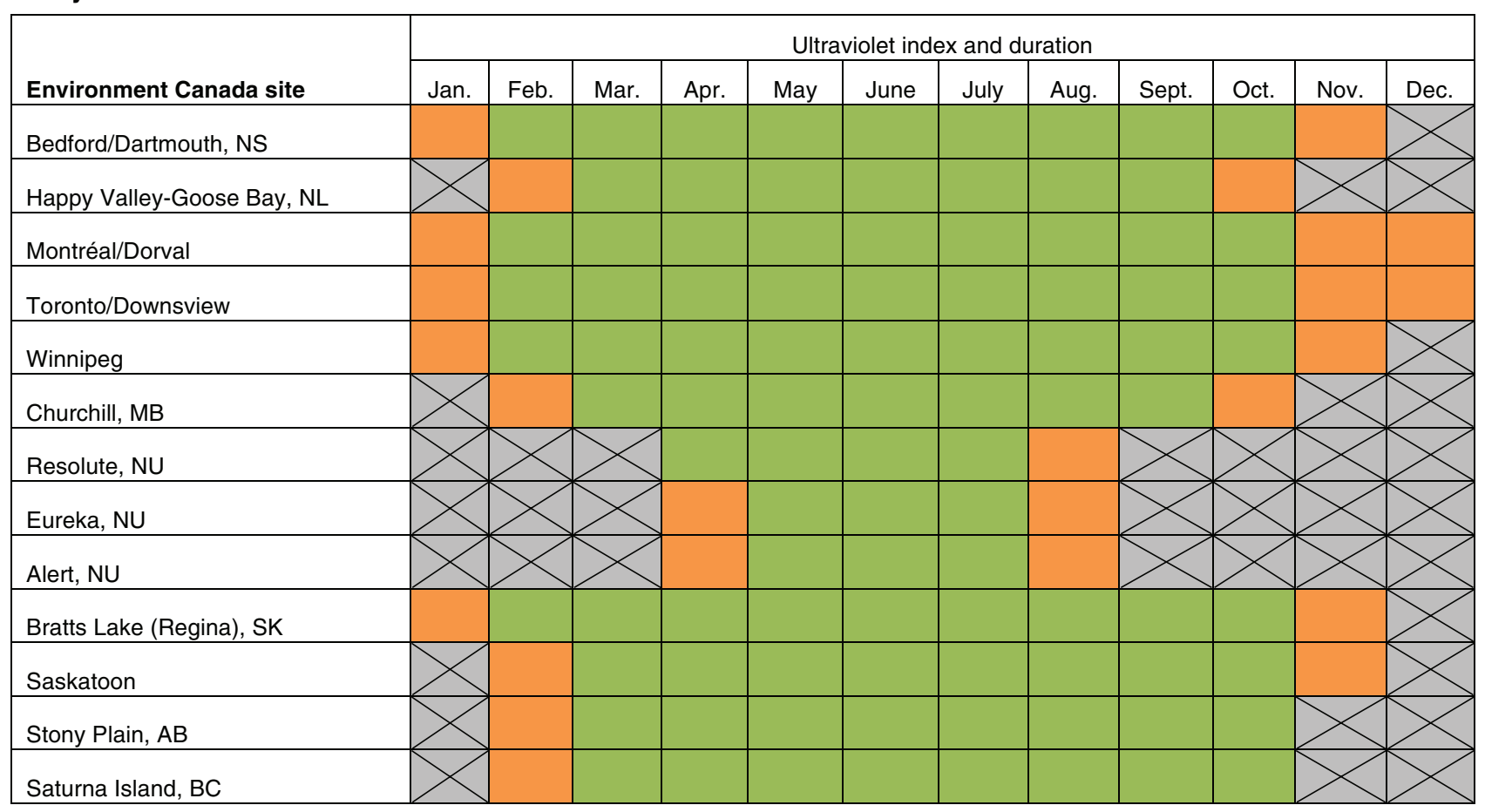

B. Persons with type II skin exposing $1 / 8$ of their body surface area to the sun to obtain $1 / 2$ of the minimal erythemal dose

\begin{tabular}{|c|c|c|c|c|c|c|c|c|c|c|c|c|}
\hline \multirow[b]{2}{*}{ Environment Canada site } & \multicolumn{12}{|c|}{ Ultraviolet index and duration } \\
\hline & Jan. & Feb. & Mar. & Apr. & May & June & July & Aug. & Sept. & Oct. & Nov. & Dec. \\
\hline \multicolumn{13}{|c|}{ Bedford/Dartmouth, NS } \\
\hline \multicolumn{13}{|c|}{ Happy Valley-Goose Bay, NL } \\
\hline \multicolumn{13}{|l|}{ Montréal/Dorval } \\
\hline \multicolumn{13}{|l|}{ Toronto/Downsview } \\
\hline \multicolumn{13}{|l|}{ Winnipeg } \\
\hline \multicolumn{13}{|l|}{ Churchill, MB } \\
\hline \multicolumn{13}{|l|}{ Resolute, NU } \\
\hline \multicolumn{13}{|l|}{ Eureka, NU } \\
\hline \multicolumn{13}{|l|}{ Alert, NU } \\
\hline \multicolumn{13}{|c|}{ Bratts Lake (Regina), SK } \\
\hline \multicolumn{13}{|l|}{ Saskatoon } \\
\hline \multicolumn{13}{|l|}{ Stony Plain, AB } \\
\hline Saturna Island, BC & & & & & & & & & & & & \\
\hline
\end{tabular}

Figure 1 (part 1): Lowest sun exposure time (in $\min$ ) required to synthesize the standard vitamin $D$ dose of $1000 \mathrm{IU}$, by site and month. (A) People with type II skin who exposed $1 / 4$ of their body surface area to $1 / 4$ of the minimal erythemal dose. (B) People with type II skin who exposed $1 / 8$ of their body surface area to $1 / 2$ of the minimal erythemal dose. 


\section{Persons with type V skin exposing $1 / 4$ of their body surface area to the sun to obtain $1 / 4$ of the minimal erythemal dose}

\begin{tabular}{|c|c|c|c|c|c|c|c|c|c|c|c|c|}
\hline \multirow[b]{2}{*}{ Environment Canada site } & \multicolumn{12}{|c|}{ Ultraviolet index and duration } \\
\hline & Jan. & Feb. & Mar. & Apr. & May & June & July & Aug. & Sept. & Oct. & Nov. & Dec. \\
\hline Bedford/Dartmouth, NS & & & & & & & & & & & & \\
\hline Goose Bay, NL & & & & & & & & & & & & \\
\hline Montréal/Dorval & & & & & & & & & & & & \\
\hline Toronto/Downsview & & & & & & & & & & & & \\
\hline Winnipeg & & & & & & & & & & & & \\
\hline Churchill, MB & & & & & & & & & & & & \\
\hline Resolute, NU & & & & & & & & & & & & \\
\hline Eureka, NU & & & & & & & & & & & & \\
\hline Alert, NU & & & & & & & & & & & & \\
\hline Bratts Lake (Regina), SK & & & & & & & & & & & & \\
\hline Saskatoon & & & & & & & & & & & & \\
\hline Stony Plain, $A B$ & & & & & & & & & & & & \\
\hline Saturna Island, BC & & & & & & & & & & & & \\
\hline
\end{tabular}

\section{Persons with type $V$ skin exposing1/8 of their body surface area to the sun to obtain $1 / 2$ of the minimal erythemal} dose

Environment Canada site
Bedford/Dartmouth, NS
Goose Bay, NL
Montréal/Dorval
Toronto/Downsview
Winnipeg
Churchill, MB
Eureka, NU
Alert, NU
Bratts Lake (Regina), SK
Saskatoon
Stony Plain, AB
Saturna Island, BC

Figure 1 (part 2): (C) People with type $V$ skin who exposed 1/4 of their body surface area to $1 / 4$ of the minimal erythemal dose. (D) People with type $V$ skin who exposed $1 / 8$ of their body surface area to $1 / 2$ of the minimal erythemal dose. Green areas, ultraviolet index $<3$ and exposure duration $\leq 30 \mathrm{~min}$; orange areas, ultraviolet index $<3$ and exposure duration $=31-60 \mathrm{~min}$; gray areas, ultraviolet index $<3$ and exposure duration $>60 \mathrm{~min}$, or exposure duration $<60 \mathrm{~min}$ and ultraviolet index $>3$ (sun protection was recommended); yellow areas, ultraviolet index $\geq 3$ (sun protection was recommended). 
during 1 hourly period in February, and required exposure times ranged between 57 and 58 minutes (Appendix 1). People in Nunavut with type $V$ skin and 1/4 of their skin exposed to the sun for 1 hour were only able to produce $1000 \mathrm{IU}$ of vitamin D in May, June and July (site dependent). No opportunities existed outside of the times when sun protection was advised for people with type $\mathrm{V}$ skin and with 1/8 of their body exposed to produce $1000 \mathrm{IU}$ of vitamin D within 1 hour during any month of the year at any site (Figure 1D).

\section{Interpretation}

\section{Main findings}

Exposure times were much higher during the fall and winter months, for people with darker skin, for people with less skin exposed and in more northern sites. In Canada, especially during the winter months, ultraviolet radiation levels are too low for it to be feasible for people to use only sunlight exposure to synthesize the recommended level of vitamin D. Fairskinned people with type II skin and with $1 / 4$ of their skin exposed had the most opportunities to synthesize $1000 \mathrm{IU}$ of vitamin $\mathrm{D}$ throughout the year, even when the periods when sun protection was recommended were excluded. However, it was impossible at many of the sites during the winter months to synthesize $1000 \mathrm{IU}$ within 1 hour with that area of skin exposed. With 1/8 of the skin exposed, people with type II skin had no opportunities to synthesize 1000 IU in January, November and December at any site. Opportunities outside of when sun protection was advised also decreased with a reduced skin surface area exposed. Darker skin types required longer exposure times compared with lighter skin types. People with type $\mathrm{V}$ skin and with $1 / 4$ of their skin exposed may not be able to synthesize $1000 \mathrm{IU}$ in February and October at some sites, in addition to January, November and December. People with type $\mathrm{V}$ skin and with $1 / 8$ of their skin exposed, who adhered to sun protection guidelines, may not be able to synthesize $1000 \mathrm{IU}$ of vitamin D during any month of the year at any site.

\section{Comparison with other studies}

The results in this study are similar to those reported in a study that assessed the feasibility of using sun exposure for vitamin D synthesis in Australia. ${ }^{9}$ It also showed that opportunities to produce enough vitamin $\mathrm{D}$ outside of the periods when sun protection is advised also decreased and when a smaller area of skin surface was exposed. Times when sun protection was recommended were included in this study, similar to a study done in Australia; 9 therefore, if these guidelines are adhered to, people are not likely to be out in the sun at those times or, if they are, the skin surface area available for vitamin $\mathrm{D}$ synthesis should be minimal. In the spring and summer months, people with type $\mathrm{V}$ skin did not have any opportunities outside of when sun protection was advised to synthesize $1000 \mathrm{IU}$ in 30 minutes or less.

Two earlier studies in North America ${ }^{21,22}$ also showed that people with darker skin types had increased difficulty in producing enough vitamin D through sun exposure alone. Although it was possible for fair-skinned people with type II skin to synthesize the standard dose of vitamin D all year at 2 sites if $1 / 4$ of their skin surface area was exposed, this was based on the unrealistic assumption that people would expose that much skin during the colder months. This limitation was discussed in one of the previous North American studies. ${ }^{21}$

Increased age, ${ }^{12}$ pregnancy and lactation, ${ }^{23}$ and obesity ${ }^{24}$ can lower the skin's ability to synthesize vitamin D; these persons may find it more difficult to rely on sun exposure alone. Specifically, in people over 70 years of age, there is a $50 \%$ reduction in the production of vitamin $\mathrm{D}$; this is important in Canada with its aging population. ${ }^{25}$ The Canadian Pediatric Society recommends $2000 \mathrm{IU}$ of vitamin D daily for pregnant women. ${ }^{26}$ People who catabolize vitamin D in skin fibroblasts at a faster rate via 24-hydroxylase also need substantially more vitamin D. ${ }^{27}$

\section{Limitations}

The average ultraviolet index data obtained from Environment Canada were collected over a large period of time and therefore yearly variations in factors that can affect ultraviolet index values should have been accounted for at most of the sites. Because this study relied on data already obtained from Environment Canada, it was difficult to standardize the specific time period for all of the sites or obtain more current data. The results may have been different a decade later. Location selection was also limited by what data were publicly available from Environment Canada. The anatomic areas corresponding to $1 / 4$ or $1 / 8$ of the total body surface area as described in this study are for adults weighing less than $80 \mathrm{~kg}$ and may not apply to children and people who are obese. Doses of $1 / 4$ and $1 / 2$ of a minimal erythemal dose are unlikely to cause sunburn because a full minimal erythemal dose only produces a small amount of erythema. Although we tried to assess the number of variables (skin type, amount of skin exposed and adherence to sun protection guidelines) that could affect the feasibility of obtaining the standard dose of vitamin $\mathrm{D}$, there are many other factors that can affect the skin's ability to synthesize vitamin D that were not included. We chose to use $1000 \mathrm{IU}$ as the standard dose of vitamin $\mathrm{D}$; however, it should be noted that this value has been under debate. A report on dietary reference intakes for vitamin $\mathrm{D}$ by the Institute of Medicine recommended doses between 600 and $800 \mathrm{IU}$ daily. ${ }^{28}$ However, other studies have recommended higher levels of vitamin $\mathrm{D}$ in blood ${ }^{29-31}$ and reported that $2000 \mathrm{IU}$ daily may not be adequate. ${ }^{32}$

\section{Conclusion}

Although sun exposure is an important source of vitamin D, it is not feasible to rely solely on sunlight in Canada. Differences in ultraviolet radiation levels across different sites and individual factors such as skin colour, amount of skin exposed and adherence to sun protection guidelines make it difficult and sometimes impossible to obtain daily recommended levels of vitamin D from the sun throughout the year. Along with sun exposure, Canadians should look to other safe sources, such as supplements and foods rich in vitamin D. ${ }^{23}$ The Canadian Dermatology Association, Health Canada and the 
World Health Organization have outlined that the use of tanning beds to obtain required recommended vitamin $\mathrm{D}$ levels is not a safe alternative. ${ }^{33}$

\section{References}

1. Holick MF. Vitamin D: important for prevention of osteoporosis, cardiovascular heart disease, type 1 diabetes, autoimmune diseases, and some cancers. South Med 7 2005;98:1024-7.

2. Abbas S, Linseisen J, Chang-Claude J. Dietary vitamin D and calcium intake and premenopausal breast cancer risk in a German case-control study. Nutr Cancer 2007;59:54-61.

3. Lin J, Manson JE, Lee I, et al. Intakes of calcium and vitamin D and breast cancer in women. Arch Intern Med 2007;167:1050-9.

4. Hoogendijk WJ, Lips P, Dik MG, et al. Depression is associated with decreased 25-hydroxyvitamin D and increased parathyroid hormone levels in older adults. Arch Gen Psychiatry 2008;65:508-12.

5. Giovannucci E, Liu Y, Hollis BW, et al. 25-Hydroxyvitamin D and risk of myocardial infarction in men: a prospective study. Arch Intern Med 2008; 168:1174-80.

6. Papaioannou A, Morin S, Cheung AM, et al. 2010 Clinical practice guidelines for the diagnosis and management of osteoporosis in Canada: summary. CMAF 2010;182:1864-73

7. Dawson-Hughes B, Mithal A, Bonjour JP, et al. IOF position statement: vitamin D recommendations for older adults. Osteoporos Int 2010;21:1151-4.

8. Langlois K, Greene-Finestone L, Little J, et al. Vitamin D status of Canadians as measured in the 2007 to 2009 Canadian Health Measures Survey. Health Rep 2010;21:47-55.

9. Stalgis-Bilinski KL, Boyages J, Salisbury EL, et al. Burning daylight: balancing vitamin D requirements with sensible sun exposure. Med 7 Aust 2011;194:345-8.

10. Holick MF. Vitamin D: importance in the prevention of cancers, type 1 diabetes, heart disease, and osteoporosis. Am 7 Clin Nutr 2004;79:362-71.

11. Holick MF. Sunlight and vitamin D for bone health and prevention of autoimmune diseases, cancers, and cardiovascular disease. Am 7 Clin Nutr 2004;80(Suppl):1678S-88S

12. MacLaughlin J, Holick MF. Aging decreases the capacity of human skin to produce vitamin D3. 7 Clin Invest 1985;76:1536-8.

13. Clemens TL, Adams JS, Hendersen SL, et al. Increased skin pigment reduces the capacity of skin to synthesise vitamin D3. Lancet 1982;1:74-6.

15. Jablonski NG, Chaplin G. The evolution of human skin colouration. 7 Hum Evol 2000;39:57-106.

14. McKenzie R, Smale D, Kotkamp M. Relationship between UVB and erythemally weighted radiation. Photochem Photobiol Sci 2004;3:252-6.

16. UV Index Calculator. Ottawa: Environment Canada; 2005. Available: http:// exp-studies.tor.ec.gc.ca/cgi-bin/uv_index_calculator (accessed 2015 May 7).

17. Armstrong BK, Kricker A. The epidemiology of UV induced skin cancer. 7 Photochem Photobiol B 2001;63:8-18.

18. Sun protection messages. Ottawa: Environment Canada; 2008. Available: www.ec .gc.ca/UV/default.asp?lang=En\&n=DCF1C20A-1 (accessed 2015 Apr. 27).
19. Matsuoka LY, Ide L, Wortsman J, et al. Sunscreens suppress cutaneous vitamin D3 synthesis. 7 Clin Endocrinol Metab 1987;64:1165-8.

20. Fitzpatrick TB. The validity and practicality of sun-reactive skin types I through IV. Arch Dermatol 1988;124:869-71.

21. Fioletov VE, McArthur LJ, Mathews TW, et al. Estimate ultraviolet exposure levels for a sufficient vitamin D status in North America. 7 Photochem Photobiol B 2010;100:57-66.

22. Terushkin V, Bender A, Psaty EL, et al. Estimated equivalency of vitamin D production from natural sun exposure versus oral vitamin D supplementation across seasons at two US latitudes. 7 Am Acad Dermatol 2010;62:929.e1-9.

23. Grant WB, Holick MF. Benefits and requirements of vitamin D for optimal health: a review. Altern Med Rev 2005;10:94-111.

24. Wortsman J, Matsuoka LY, Chen TC, et al. Decreased bioavailability of vitamin D in obesity. Am 7 Clin Nutr 2000;72:690-3.

25. MacLaughlin J, Holick MF. Aging decreases the capacity of human skin to produce vitamin D3. 7 Clin Invest 1985;76:1536-8.

26. Vitamin D supplementation: recommendations for Canadian mothers and infants. Paediatr Child Health (Oxford) 2007;12:583-9.

27. Awumey EM, Mitra DA, Hollis BW, et al. Vitamin D metabolism is altered in Asian Indians in the southern United States: a clinical research center study. 7 Clin Endocrinol Metab 1998;83:169-73.

28. Ross AC, et al. The 2011 report on dietary reference intakes for calcium and vitamin D for the Institute of Medicine: what clinicians need to know. 7 Clin Endocrinol Metab 2011;96:53-8.

29. Schwalfenberg GK, Whiting SJ. A Canadian response to the 2010 Institute of Medicine vitamin D and calcium guidelines. Public Health Nutr 2011;14:746-8.

30. Grant WB, et al. An estimate of the economic burden and premature deaths due to vitamin D deficiency in Canada. Mol Nutr Food Res 2010;54:1172-81.

31. Amrein K, et al. Evidence for a u-shaped relationship between prehospital vitamin D status and mortality: a cohort study. 7 Clin Endocrinol Metab 2014;99:1461-9.

32. Schwalfenberg GK, Genuis SJ. Vitamin D supplementation in a nursing home population. Mol Nutr Food Res 2010;54:1072-6.

33. Canadian Dermatology Association position statement: safe and effective way to maintain adequate levels of vitamin D. Ottawa: Canadian Dermatology Association, 2007. Available: www.dermatology.ca/wp-content/uploads/2013/09/CDAposition-statement-on-Vitamin-D-Aug-2013.pdf (accessed 2015 May 7).

Affiliations: Faculty of Medicine (Gill); Department of Dermatology and Skin Sciences (Kalia), The University of British Columbia, Vancouver, BC

Contributors: All of the authors made substantial contributions to the conception and design and acquisition of the data, and interpretation of the data. All of the authors drafted the article and revised it critically for important intellectual content, approved the version to be published and agreed to act as guarantors of the work.

Supplemental information: For reviewer comments and the original submission of this manuscript, see www.cmajopen.ca/content/3/3/E258/ suppl/DC1 